\title{
A Bibliometric Analysis of the First Twenty Years of Soft Computing
}

\author{
José M. Merigó ${ }^{1}$, Enrique Herrera-Viedma ${ }^{2}$, Manuel J. Cobo ${ }^{3}$, Sigifredo Laengle ${ }^{1}$, and \\ Daniela Rivas $^{1}$ \\ ${ }^{1}$ Dep. Management Control and Information Systems, School of Economics and Business, \\ University of Chile, Santiago 8330105, Chile \\ ${ }^{2}$ Department of Computer Science and Artificial Intelligence, University of Granada, \\ Av. Periodista Daniel Saucedo s/n, Granada, Spain \\ ${ }^{3}$ Department of Computer Science and Engineering, University of Cadiz, Cadiz, Spain \\ jmerigo@fen.uchile.cl; viedma@decsai.ugr.es; \\ manueljesus.cobo@uca.es; slaengle@fen.uchile.cl; \\ drivasefen.uchile.cl
}

\begin{abstract}
Soft Computing was launched in 1997. Today, the journal is becoming twenty years old. Motivated by this anniversary, this article develops a bibliometric analysis of the journal in order to identify the leading trends of the journal in terms of publications and citations. The work considers several issues including the leading authors, institutions and countries. The study also uses a software to develop a graphical analysis. The results show a significant increase of the journal during the last years that has consolidated the journal as a leading one in the field.
\end{abstract}

Keywords: Soft Computing; Web of Science; Bibliometrics; VOS Viewer.

\section{$1 \quad$ Introduction}

The Soft Computing (SC) journal is a leading international journal in the field of Soft Computing, which encompasses a wide range of theories including fuzzy sets and systems, neural networks, evolutionary computation, probabilistic reasoning and other related theories. The journal published its first issue in 1997 and since then it has increased significantly becoming today a monthly journal. The journal is indexed in Web of Science Core Collection and received an impact factor of 1.630 in the latest Journal Citation Reports being in the 56th position of 130 in the category of Computer Science, Artificial Intelligence. Antonio Di Nola, the founding editor-in-chief, created the journal. Today, he currently runs the journal together with Vincenzo Loia. Both are from the University of Salerno, Italy. Soft Computing is published by Springer international publisher.

In 2017, SC becomes twenty years old. To mark this anniversary, this work presents a bibliometric overview of the journal in order to identify the leading trends that have occurred over the last twenty years. The study identifies the most productive 
authors, institutions and countries and develops a general analysis of the publications and citations of the journal. The work also develops a mapping analysis [1] in order to visualize the bibliographic material by using the visualization of similarities (VOS) viewer software [2].

Observe that many other journals have already developed a bibliometric overview of their journals, especially for the celebration of a special event. Among others, it is worth mentioning the Knowledge-Based Systems [3], International Journal of Intelligent Systems [4], Journal of Business Research [5], Journal of Business \& Industrial Marketing [6], and the European Journal of Operational Research [7].

The remainder of the work is structured as follows. Section 2 presents the bibliometric approach to be used in the paper. Section 3 presents the most productive authors, institutions and countries. Section 4 studies the structure of the publications and citations of the journal. Section 5 presents the graphical analysis with VOS viewer software. Section 6 summarizes the main findings and conclusions of the study.

\section{Bibliometric methods}

The work uses different bibliometric methods. Observe that bibliometrics is usually defined as the science that studies quantitatively the bibliographic material [8-9]. In the literature it is very common to develop bibliometric studies of a wide range of issues including topics [10-11], journals [12], authors [13], universities [14] and countries [15]. Due to the strong development of computers, bibliometrics has become a very powerful technique for providing a general overview of a research field.

The study uses the Web of Science Core Collection database. The search was carried out between November 2016 and January 2017 and finds all the documents in the journal since its creation in 1997. Up to 2016, the journal has published 2331 documents which decreases to 2037 if only considering articles, reviews and notes. It has received 17523 citations with a ratio of 7.52 cites per paper. The $h$-index is 48 , that is, of the 2331 documents published in the journal, 48 have received 48 citations or more.

The analysis uses a wide range of bibliometric indicators [16] including the total number of publications and citations, the ratio cites per paper, the $h$-index [17-18] and citations thresholds. The objective is to provide a general overview of the bibliographic material. The main reason for doing so is because there are different perspectives to consider when analyzing the bibliographic material. From a general point of view [19], the two main perspectives are the number of publications that reflect the productivity and the number of citations that focus on the influence and popularity of a document.

Additionally, the work uses bibliographic coupling [20] and co-citation analysis [21] to develop the graphical analysis. Note that the VOS viewer software is used to visualize the bibliographic material [2]. Recall that co-citation occurs when two documents receive a citation from the same source and bibliographic coupling when two documents cite the same third work. 


\section{Leading Authors, Institutions and Countries of SC}

Many authors have made significant contributions to the journal since 1997. Table 1 presents a list with the twenty most productive authors until 31 December 2016.

Table 1. Most productive authors in SC

\begin{tabular}{clcccc}
\hline R & Author Name & TP & TC & C/P & H \\
\hline 1 & Pedrycz, W & 27 & 97 & 3,59 & 5 \\
2 & Buckley, JJ & 18 & 252 & 14,00 & 9 \\
3 & Chajda, I & 18 & 61 & 3,39 & 4 \\
4 & Herrera, F & 16 & 1023 & 63,94 & 11 \\
5 & Dvurecenskij, A & 16 & 111 & 6,94 & 5 \\
6 & Allahviranloo, T & 14 & 130 & 9,29 & 7 \\
7 & Wang, ST & 13 & 93 & 7,15 & 5 \\
8 & Jiao, LC & 13 & 26 & 2,00 & 2 \\
9 & Zhang, MJ & 12 & 33 & 2,75 & 3 \\
10 & Liu, ZQ & 12 & 98 & 8,17 & 5 \\
11 & Alba, E & 12 & 67 & 5,58 & 4 \\
12 & Davvaz, B & 10 & 355 & 35,50 & 7 \\
13 & Yager, RR & 10 & 173 & 17,30 & 3 \\
14 & Hong, TP & 10 & 122 & 12,20 & 4 \\
15 & Chung, FL & 10 & 40 & 4,00 & 4 \\
16 & Yang, SX & 9 & 211 & 23,44 & 5 \\
17 & Melin, P & 9 & 116 & 12,89 & 4 \\
18 & Yao, X & 9 & 177 & 19,67 & 5 \\
19 & Sanchez, L & 8 & 469 & 58,63 & 5 \\
20 & Lozano, M & 8 & 188 & 23,50 & 8 \\
\hline
\end{tabular}

Witold Pedrycz clearly obtains the first position with twenty-seven articles. However, in terms of citations and the $h$-index, Francisco Herrera obtains the most significant results far away from the rest of authors.

Next, let us look into leading institutions. For doing so, Table 2 presents the twenty most productive institutions.

The University of Granada clearly leads the ranking obtaining the most significant results in number of paper, citations and the $h$-index.

A further interesting issue is to consider the country affiliation of the institutions in order to analyse the geographical regions with a highest productivity in SC. Table 3 presents the twenty most productive countries.

China clearly dominates the list with more than twice the number of papers of Spain, which is in the second place. The USA and the UK obtain the third and fourth position, respectively. However, when normalizing per person, Czech Republic and Slovakia obtain the most remarkable results. 
Table 2. Most productive institutions in SC

\begin{tabular}{clcccc}
\hline $\mathrm{R}$ & Institution & $\mathrm{TP}$ & $\mathrm{TC}$ & $\mathrm{H}$ & $\mathrm{C} / \mathrm{P}$ \\
\hline 1 & U Granada & 56 & 1628 & 18 & 29,07 \\
2 & Slovak Academy Sci & 43 & 167 & 6 & 3,88 \\
3 & Islamic Azad U & 42 & 375 & 11 & 8,93 \\
4 & Chinese Academy Sci & 41 & 182 & 7 & 4,44 \\
5 & Xidian U & 32 & 72 & 5 & 2,25 \\
6 & Palacky U Olomouc & 32 & 121 & 7 & 3,78 \\
7 & Indian Institute Techn & 31 & 246 & 9 & 7,94 \\
8 & U Alberta & 30 & 110 & 6 & 3,67 \\
9 & Czech Academy Sci & 24 & 382 & 8 & 15,92 \\
10 & U Salerno & 23 & 134 & 6 & 5,83 \\
11 & Jiangnan U & 22 & 124 & 6 & 5,64 \\
12 & City U Hong Kong & 22 & 189 & 9 & 8,59 \\
13 & Hong Kong Polytechnic U & 22 & 143 & 7 & 6,50 \\
14 & U Malaga & 21 & 88 & 5 & 4,19 \\
15 & Tsinghua U & 19 & 157 & 7 & 8,26 \\
16 & U Jaen & 19 & 903 & 11 & 47,53 \\
17 & U Ostrava & 19 & 157 & 7 & 8,26 \\
18 & U Alabama Birmingham & 18 & 261 & 9 & 14,50 \\
19 & Slovak U Tech Bratislava & 17 & 162 & 6 & 9,53 \\
20 & Polish Academy Sci & 17 & 77 & 4 & 4,53 \\
\hline
\end{tabular}

Table 3. Most productive countries in SC

\begin{tabular}{clcccc}
\hline R & Country & TP & TC & H & C/P \\
\hline 1 & China & 546 & 2893 & 23 & 5,30 \\
2 & Spain & 230 & 2793 & 23 & 12,14 \\
3 & USA & 197 & 1676 & 18 & 8,51 \\
4 & UK & 178 & 1587 & 16 & 8,92 \\
5 & Iran & 140 & 1177 & 17 & 8,41 \\
6 & India & 132 & 670 & 13 & 5,08 \\
7 & Taiwan & 128 & 698 & 13 & 5,45 \\
8 & Italy & 127 & 972 & 14 & 7,65 \\
9 & Czech Republic & 107 & 724 & 13 & 6,77 \\
10 & Japan & 94 & 568 & 11 & 6,04 \\
11 & Canada & 77 & 421 & 11 & 5,47 \\
12 & Germany & 56 & 865 & 10 & 15,45 \\
13 & Slovakia & 54 & 291 & 9 & 5,39 \\
14 & Turkey & 53 & 369 & 10 & 6,96 \\
15 & Australia & 53 & 362 & 9 & 6,83 \\
16 & Poland & 52 & 265 & 10 & 5,10 \\
17 & France & 52 & 421 & 12 & 8,10 \\
18 & Romania & 51 & 336 & 8 & 6,59 \\
19 & South Korea & 49 & 183 & 7 & 3,73 \\
20 & Greece & 37 & 197 & 7 & 5,32 \\
\hline
\end{tabular}




\section{$4 \quad$ Publication and Citation Structure}

Soft Computing started publishing papers in 1997 and since then it has grown significantly. Table 4 presents the results considering several citation thresholds.

\begin{tabular}{cccccc}
\multicolumn{7}{c}{ Table 4. Citation structure of SC } \\
\hline Year & TP & $\geq 100$ & $\geq 50$ & $\geq 10$ & $\geq 1$ \\
\hline 1997 & 21 & 2 & 1 & 3 & 8 \\
1998 & 20 & 1 & 0 & 3 & 6 \\
1999 & 32 & 1 & 0 & 8 & 9 \\
2000 & 34 & 1 & 0 & 5 & 11 \\
2001 & 62 & 0 & 1 & 7 & 16 \\
2002 & 64 & 0 & 3 & 12 & 20 \\
2003 & 68 & 1 & 1 & 10 & 20 \\
2004 & 62 & 0 & 1 & 7 & 20 \\
2005 & 91 & 1 & 0 & 11 & 26 \\
2006 & 128 & 1 & 6 & 20 & 37 \\
2007 & 115 & 2 & 4 & 19 & 34 \\
2008 & 117 & 0 & 2 & 27 & 35 \\
2009 & 98 & 0 & 4 & 27 & 21 \\
2010 & 111 & 2 & 1 & 15 & 35 \\
2011 & 188 & 0 & 4 & 31 & 59 \\
2012 & 161 & 0 & 1 & 20 & 62 \\
2013 & 171 & 0 & 0 & 16 & 79 \\
2014 & 186 & 0 & 0 & 7 & 82 \\
2015 & 261 & 0 & 0 & 3 & 62 \\
2016 & 341 & 0 & 0 & 0 & 28 \\
\hline
\end{tabular}

Another interesting issue to consider is those variables that cite more the journal. For doing so, Table 5 shows the journals, authors, universities and countries that have cited more SC.

Another interesting issue to analyze is to identify those papers that are most cited in the documents published in the journal. To assess this issue, let us use VOS viewer software in a co-citation analysis of documents. Table 6 presents the results.

The most cited paper in the journal is the seminal paper of Lotfi A. Zadeh about fuzzy sets. Note that this paper is the most cited paper in computer science of all-time and among the fifty most cited papers of all-time of all sciences [16]. Note that the references of the table only include the first author of each document. The total link strength indicates the connections with other documents that at least have received twenty citations in the journal. 
Table 5. Citing articles of SC

\begin{tabular}{clclc}
\hline R & University & TP & Country & TP \\
\hline 1 & U Granada & 300 & China & 2409 \\
2 & Islamic Azad U & 182 & Spain & 925 \\
3 & U Jaen & 137 & Iran & 660 \\
4 & King Abdulaziz U & 104 & USA & 549 \\
5 & Chinese Acad Sci & 104 & UK & 485 \\
6 & Nanyang Tech U & 90 & India & 459 \\
7 & Palacky U Olomouc & 87 & Taiwan & 381 \\
8 & CNRS - France & 85 & Italy & 327 \\
9 & Cordoba U & 84 & Czech Rep & 274 \\
10 & U Yazd & 82 & Turkey & 257 \\
11 & Indian Inst Tech & 80 & Canada & 223 \\
12 & Central South U & 80 & France & 214 \\
13 & Slovak Acad Sci & 79 & Australia & 201 \\
14 & Xidian U & 69 & South Korea & 183 \\
15 & Huazhong U Sci Tech & 67 & Poland & 166 \\
16 & Shahid Bahonar U Kerman & 66 & Malaysia & 161 \\
17 & Polish Acad Sci & 65 & Japan & 161 \\
18 & Northeastern U China & 64 & Saudi Arabia & 153 \\
19 & Ghent U & 63 & Romania & 148 \\
20 & Tsinghua U & 62 & Slovakia & 144 \\
\hline
\end{tabular}

Table 6. Most cited documents in SC publications

\begin{tabular}{lllccc}
\hline R & Year & Cited Reference & Type & Citations & TLS \\
\hline 1 & 1965 & Zadeh LA, Inform Control, v8, p338 & A & 203 & 137 \\
2 & 1989 & Goldberg DE, Genetic Algorithms & B & 124 & 90 \\
3 & 1995 & Kennedy J, IEEE Int Conf Neural Networks Proc, vols 1-6, p1942 & C & 98 & 81 \\
4 & 2002 & Deb K, IEEE T Evolut Comput, v6, p182 & A & 92 & 74 \\
5 & 1997 & Storn R, J Global Optim, v11, p341 & A & 82 & 73 \\
6 & 1975 & Zadeh LA, Inform Sciences, v8, p199 & A & 78 & 65 \\
7 & 1981 & Bezdek JC, Pattern Recognition & B & 62 & 37 \\
8 & 1998 & Hajek P, Metamathematics of Fuzzy Logic & B & 55 & 40 \\
9 & 1975 & Holland JH, Adaptation in Natural and Artificial Systems & B & 55 & 45 \\
10 & 2001 & Deb K, Multiobjective Optimization & B & 52 & 50 \\
11 & 2000 & Dvurecenskij A, New Trends in Quantum Structures & B & 50 & 43 \\
12 & 1992 & KozaJR, Genetic Programming & B & 45 & 24 \\
13 & 2009 & Garcia S, J Heuristics, v15, p617 & A & 44 & 41 \\
14 & 1999 & Zitzler E, IEEE T Evolut Comput, v3, p257 & B & 39 & 28 \\
15 & 1993 & Quinlan JR, C4.5: Programs for Machine Learning & A & 38 & 34 \\
16 & 2006 & Demsar J, J Mach Learn Res, v7, p1 & A & 38 & 28 \\
17 & 1985 & Takagi T, IEEE T Syst Man Cyb, v15, p116 & B & 38 & 17 \\
18 & 1998 & Vapnik VN, Statistical Learning Theory & A & 37 & 32 \\
19 & 1986 & Atanassov KT, Fuzzy Set Syst, v20, p87 & A & 37 & 23 \\
20 & 1982 & Pawlak Z, Int J Comput Inf Sci, v11, p341 & & &
\end{tabular}

Abbreviations: $\mathrm{A}=$ Article; $\mathrm{B}=\mathrm{Book} ; \mathrm{C}=$ Conference proceedings; TLS $=$ Total Link Strength. 


\section{Graphical Visualization of SC}

VOS viewer software collects the bibliographic material providing general maps by using several bibliometric indicators including bibliographic coupling, co-citation, coauthorship, citation analysis and co-occurrence of keywords [2]. This subsection develops a graphical visualization of the publications of SC by using VOS viewer. By doing so, the reader obtains a more general representation of the results and how they are connected [22].

First, let us consider co-citation of journals. Recall, that it occurs when two documents from different journals receive a citation from the same third document of another journal [21]. The graph visualizes the most cited journals and the network connections indicate those journals that are more co-cited. Figure 1 shows the results considering a threshold of fifty citations and the one hundred most representative cocitation connections.

Fuzzy Sets and Systems is the most cited journal in SC followed by Information Sciences and SC itself. The journals that form the core strongly connect to the field of computer science with a strong focus on the emerging theories of soft computing and related issues. It is also worth noting that the Lecture Notes in Computer Science has a strong influence in the journal.

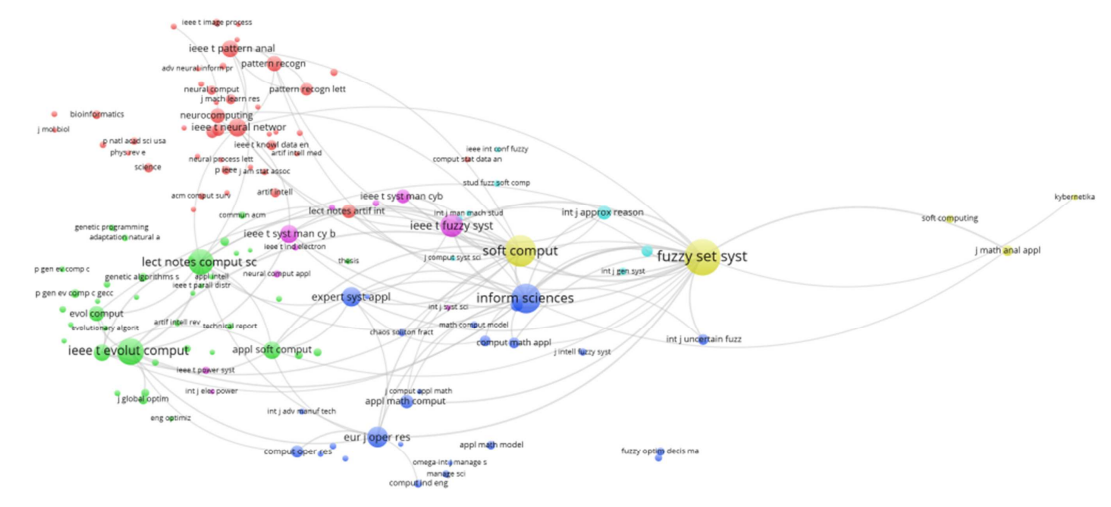

Fig 1. Co-citation of journals

Fuzzy Sets and Systems is the most cited journal in SC followed by Information Sciences and SC itself. The journals that form the core strongly connect to the field of computer science with a strong focus on the emerging theories of soft computing and related issues. It is also worth noting that the Lecture Notes in Computer Science has a strong influence in the journal.

Next, let us analyse bibliographic coupling of authors that publish in SC. Bibliographic coupling [20] of authors analyzes the authors of two documents that cite the same third document. Thus, in the map appears the name of the authors of these doc- 
uments, particularly, the most productive authors when dealing with all the set of documents. And the network connections show those authors that cite the same bibliographic material with the aim of identifying authors with similar research profiles. Figure 2 visualizes the results considering a threshold of five documents published in the journal and the one hundred most representative bibliographic coupling connections.

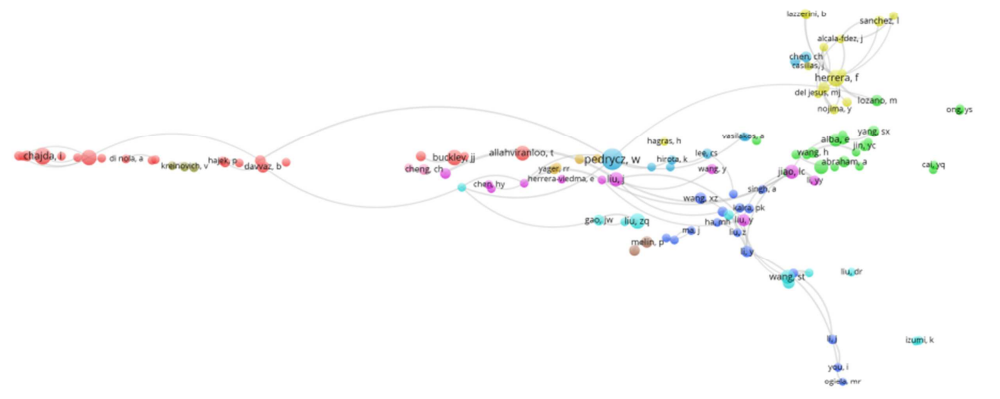

Fig 2. Bibliographic coupling of authors

Witold Pedrycz and Francisco Herrera form the most representative cores. In general, the results are quite consistent with the results of Table 1. The main advantage of Figure 2 is that it visualizes those authors with similar profiles either because they work on similar topics or because they are co-authors.

Bibliographic coupling can also be studied from the institutional perspective. Here the difference is that the map visualizes the most productive institutions in terms of the institutional affiliation of the authors that publish in SC. The network connections represent the authors of institutions that cite many times the same bibliographic references showing similar research profiles. Figure 3 shows the results with a threshold of five documents published in the journal and the one hundred most significant bibliographic coupling connections. 


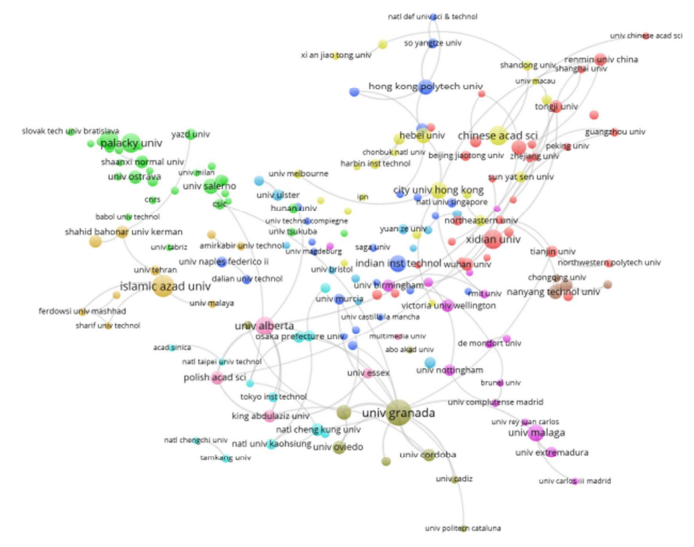

Fig 3. Bibliographic coupling of institutions

The University of Granada is the most productive institution and represents one of the key cores of the journal. The results of this figure are in accordance to the results of Table 2 although in the figure the universities appear according to their research profile connections with other institutions.

Finally, let us focus on the most common keywords used in the journal in order to identify the leading topics that SC is publishing. For doing so, the study considers the author keywords that usually appear below the abstract. The map shows those keywords with the highest occurrence inside the set of documents of SC and the network connections indicate the keywords that tend to appear frequently in the same documents. Figure 4 presents the results considering a threshold of five occurrences and the one hundred most representative co-occurrence connections.

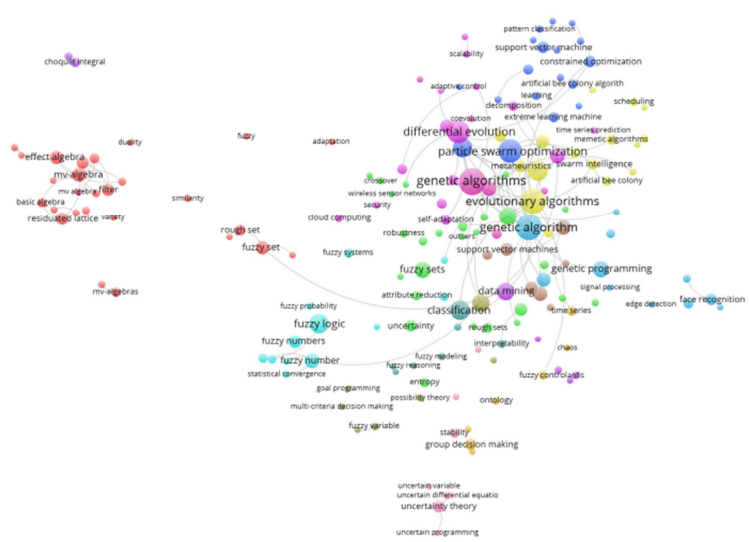

Fig. 4. Co-occurrence of author keywords 
Genetic and evolutionary algorithms are the most common keywords that appear in the journal. Some other popular topics are particle swam optimization, neural networks and fuzzy logic. Note that since soft computing is a trivial keyword, it does not appear so much in the documents published in the journal. Figure 4 clearly shows that today evolutionary computation has been the leading topic in the journal. On the other hand, the other main parts of soft computing, such as neural networks and fuzzy logic, have a significant position in the journal although currently their publication volume is well below that of evolutionary computation.

\section{Conclusions}

Motivated by the twentieth anniversary of the journal, this study has presented a bibliometric overview of the publications of the journal between 1997 and 2016. The results show a strong increase of the journal becoming a monthly journal since 2005 . Today, the journal publishes more than three hundred documents every year and is recognized as one of the leading journals in the field of computer science. The study uses several bibliometric indicators to identify the leading trends occurring in the journal.

The University of Granada (Spain) is the most influential institution in the journal although China is the most productive country. However, if the numbers per capita are normalized, then, the Spanish institutions achieve a more remarkable result. In terms of authors, Witold Pedrycz is the most productive author in the journal while Francisco Herrera is the most influential one.

The VOS viewer software provides a deeper visualization of the publication and citation structure of the key variables of the journal. The network connections show which authors and/or institutions are connected between them in terms of bibliographic coupling and co-citation.

In future research, this study will expand the analysis considering additional bibliometric issues in the study including a deeper temporal evolution of the publications and more results with the VOS viewer software. Note that other journals will be considered in order to provide a better view of the publications in this field of study.

\section{Acknowledgements}

Support from the Chilean Government through the Fondecyt Regular program (project number 1160286) is gratefully acknowledged.

\section{References}

1. Cobo, M. J., Lopez-Herrera, A. G., Herrera-Viedma, E., Herrera, F.: SciMAT: A new science mapping analysis software tool. Journal of the American Society for Information Science and Technology, 63, 1609-1630 (2012). 
2. Van Eck, N. J., Waltman, L.: Software survey: VOSviewer, a computer program for bibliometric mapping. Scientometrics, 84, 523-538 (2010).

3. Cobo, M. J., Martínez, M. A., Gutiérrez-Salcedo, M., Fujita, H., Herrera-Viedma, E.: 25 years at Knowledge-Based Systems: A bibliometric analysis. Knowledge-Based Systems, 80, 3-13 (2015).

4. Merigó, J. M., Blanco-Mesa, F., Gil-Lafuente, A. M., Yager, R. R.: Thirty years of the International Journal of Intelligent Systems: A bibliometric review. International Journal of Intelligent Systems, 32, 526-554 (2017).

5. Merigó, J. M., Mas-Tur, A., Roig-Tierno, N., Ribeiro-Soriano, D.: A bibliometric overview of the Journal of Business Research between 1973 and 2014. Journal of Business Research, 68, 2645-2653 (2015).

6. Valenzuela, L., Merigó, J. M., Johnston, W., Nicolás, C., Jaramillo, F.: Thirty years of the Journal of Business \& Industrial Marketing: A bibliometric analysis. Journal of Business \& Industrial Marketing, 32, 1-18 (2017).

7. Laengle, S., Merigó, J. M., Miranda, J., Slowinski, R., Bomze, I., Borgonovo, E., Dyson, R. G., Oliveira, J. F., Teunter, R.: Forty years of the European Journal of Operational Research: A bibliometric overview. European Journal of Operational Research, http://dx.doi.org/10.1016/j.ejor.2017.04.027 (2017).

8. Broadus, R. N.: Toward a definition of "Bibliometrics". Scientometrics, 12, 373-379, (1987).

9. Pritchard, A.: Statistical bibliography or bibliometrics? Journal of Documentation, 25, 348-349 (1969).

10. Emrouznejad, A., Marra, M.: Ordered weighted averaging operators 1988-2014. A citation based literature survey. International Journal of Intelligent Systems, 29, 994-1014 (2014).

11. Yu, D.: A scientometrics review on aggregation operator research. Scientometrics, 105, 115-133 (2015).

12. Thongpapanl, N.: The changing landscape of technology and innovation management: An updated ranking of journals in the field. Technovation, 32, 257-271 (2012).

13. Coupé, T.: Revealed performances: Worldwide rankings of economists and economics departments, 1990-2000. Journal of the European Economic Association, 1, 1309-1345 (2003).

14. Linton, J. D.: Perspective: Ranking Business Schools on the management of technology. Journal of Product Innovation Management, 21, 416-430 (2004).

15. Bonilla, C., Merigó, J. M., Torres-Abad, C.: Economics in Latin America: A bibliometric analysis. Scientometrics, 105, 1239-1252 (2015).

16. Merigó, J. M., Gil-Lafuente, A. M., Yager, R. R.: An overview of fuzzy research with bibliometric indicators. Applied Soft Computing, 27, 420-433 (2015).

17. Alonso, S., Cabrerizo, F. J., Herrera-Viedma, E., Herrera, F.: H-index: A review focused on its variants, computation, and standarization for different scientific fields. Journal of Informetrics, 3, 273-289 (2009).

18. Hirsch, J. E.: An index to quantify an individual's scientific research output. Proceedings of the National Academy of Sciences of the United States of America, 102, 16569-16572 (2005).

19. Podsakoff, P. M., MacKenzie, S. B., Podsakoff, N. P., Bachrach, D. G.: Scholarly influence in the field of management: A bibliometric analysis of the determinants of university and author impact in the management literature in the past quarter century. Journal of Management, 34, 641-720 (2008).

20. Kessler, M. M.: Bibliographic coupling between scientific papers. American Documentation, 14, 10-25 (1963). 
21. Small, H.: Co-citation in the scientific literature: A new measure of the relationship between two documents. Journal of the American Society for Information Science, 24, 265 269 (1973).

22. Merigó, J. M., Cancino, C., Coronado, F., Urbano, D.: Academic research in innovation: A country analysis. Scientometrics, 108, 559-593 (2016). 